\title{
ANALISIS TINGKAT PENERIMAAN PROGRAM "BEBERES SENDIRI PADA RESTORAN KFC MENGGUNAKAN METODE STRUCTURAL EQUATION MODELLING - PARTIAL LEAST SQUARE (SEM-PLS)
}

\author{
Anisa Muthia*1, Tabah Heri Setiawan², Gerry Sastro ${ }^{3}$ \\ 1,2,3Program Studi Matematika, FMIPA Universitas Pamulang \\ anisamuthia.mks@gmail.com*1 dosen00685@unpam.ac.id $^{2}$ \\ dosen00000@unpam.ac.id ${ }^{3}$
}

\begin{abstract}
Some fast food restaurants are starting to adopt the culture of "clean it yourself", which is an activity to tidy up the table from food wrappers to be thrown into the waste container provided by the restaurant. This research aims to analyze the level of acceptance of the "clean it yourself" program and affecting factors. This research uses quantitative method with three independent variables adapted from various sources namely Environmental Awareness, Facilities and Program Campaign, then one dependent variable namely Acceptance Level. There are 168 respondents who were used as samples with using purposive sampling technique. For data processing, this research uses the PLS-SEM method with the SmartPLS version 3.3.2 application. The result of this research is that there is a positive, strong and significant effect between Environmental Awareness factor and the level of acceptance. Then there is a positive, weak and insignificant effect between the Facilities factor and the level of acceptance, there is a positive, moderate and significant effect between the Program Campaign factor and the level of acceptance. And the three independent variables affect the dependent variable significantly by $50.7 \%$.
\end{abstract}

Keywords: Acceptance Level, PLS-SEM, KFC Program.

\begin{abstract}
Abstrak
Beberapa restoran cepat saji mulai menerapkan budaya "Beberes Sendiri", yaitu suatu kegiatan untuk merapikan meja dari pembungkus makanan untuk selanjutnya dibuang ke tempat sampah yang disediakan oleh restoran. Penelitian ini bertujuan untuk menganalisis tingkat penerimaan pada program "Beberes Sendiri" serta faktor-faktor yang mempengaruhi. Penelitian ini menggunakan metode kuantitatif dengan tiga variabel independen yang diadaptasi dari berbagai sumber yaitu Kesadaran Lingkungan, Sarana dan Kampanye Program, serta satu variabel dependen yaitu Tingkat Penerimaan. Terdapat 168 responden yang digunakan sebagai sampel dengan pengambilan sampel menggunakan teknik purposive sampling. Pengolahan data menggunakan metode PLS-SEM dengan bantuan aplikasi SmartPLS versi 3.3.2. Hasil pada penelitian ini adalah terdapat pengaruh positif, kuat dan signifikan antara faktor kesadaran lingkungan dengan tingkat penerimaan. Terdapat pengaruh positif, lemah serta tidak signifikan antara faktor sarana dengan tingkat penerimaan, terdapat pengaruh positif, menengah serta signifikan antara faktor kampanye program dengan tingkat penerimaan. Dan ketiga variabel independen mempengaruhi variabel dependen secara signifikan sebesar $50,7 \%$.
\end{abstract}

Kata kunci: Tingkat Penerimaan, SEM-PLS, KFC Program. 
Jurnal Lebesgue : Jurnal Ilmiah Pendidikan Matematika, Matematika dan Statistika

Anisa Muthia, Tabah Heri Setiawan, Gerry Sastro

Volume 2, No. 1, April 2021 hal.22-33

DOI Artikel : $10.46306 / 1 b . v 2 \mathrm{i} 1.51$

\section{PENDAHULUAN}

Menurut Kamus Besar Bahasa Indonesia (KBBI) bersih adalah bebas dari kotoran dan kebersihan adalah perihal keadaan, bersih: kesucian; kemurnian; atau ketulenan. Sedangkan menurut Wikipedia Indonesia (2020) kebersihan adalah keadaan bebas dari kotoran, termasuk di antaranya, debu, sampah, dan bau. Pentingnya kebersihan lingkungan karena kesehatan kita dan keberlangsungan hidup manusia di bumi secara langsung bergantung pada kesehatan lingkungan, jika kita hidup di lingkungan yang bersih maka kita dapat hidup sehat, aman dan nyaman. Hal itu dapat dicapai dengan memahami pentingnya menjaga lingkungan yang bersih.

Pemerintah atau instansi terkait bahkan masyarakat harus saling mendukung satu sama lain untuk kebiasaan baik dengan kegiatan kampanye membuang sampah pada tempatnya agar hal itu dapat dimulai sedikit demi sedikit lalu diterapkan dalam kehidupan sehari hari. Maka dari itu beberapa restoran cepat saji mulai menerapkan budaya "Beberes Sendiri" yaitu suatu kegiatan untuk merapikan meja dari sisa pembungkus makanan untuk selanjutnya dibuang ke tempat sampah yang disediakan oleh restoran. Program tersebut diterapkan di Indonesia dengan harapan dapat meningkatkan kesadaran masyarakat akan perilaku kebersihan.

Kegiatan beberes sendiri saat di restoran cepat saji juga sudah biasa dilakukan oleh seseorang bernama Kelsi Sawitri (25), kebiasaan tersebut ia bawa setelah tinggal di Jepang untuk sementara sekitar satu tahun. Kelsi mengatakan "Di Jepang makan di ramen, McD, KFC, Udon beberes nampan sendiri. Tapi kalau di resto 'all you can eat' enggak”. Memang tidak ada imbauan secara langsung untuk pengunjung membereskan nampan sendiri setelah makan, tetapi budaya tersebut sudah menjadi kesadaran di masyarakat Jepang. Menurut Kelsi bahwa di Jepang, di restoran biasanya sudah tersedia tempat untuk meletakkan nampan setelah makan. Bahkan saat di restoran udon (berupa makanan berkuah) yang menggunakan mangkuk berbahan keramik atau bahan berat lainnya. Sebenarnya di restoran cepat saji yang ada di Indonesia sudah tersedia tempat sampah berikut tempat untuk meletakkan nampannya, sehingga seharusnya para pelanggan memiliki kesadaran untuk merapikan meja dan meletakkan kembali nampan setelah makan.

Jika di Indonesia, makanan cepat saji biasanya menggunakan piring kertas, mangkuk dan gelas styrofoam yang notabene akan dijadikan sampah setelah digunakan. Kemudian membiarkan sampah tergeletak di meja seringkali dianggap hal yang sepele karena kurangnya kesadaran bahwa sisa bungkus makanan tersebut merupakan golongan sampah yang seharusnya kita buang pada tempatnya, dan merasa bahwa saat kita makan di restoran cepat saji jumlah tagihan yang kita bayarkan sudah termasuk dengan layanan membersihkan sisa 
Jurnal Lebesgue : Jurnal Ilmiah Pendidikan Matematika, Matematika dan Statistika

Anisa Muthia, Tabah Heri Setiawan, Gerry Sastro

Volume 2, No. 1, April 2021 hal.22-33

DOI Artikel : $10.46306 / 1 b . v 2 \mathrm{i} 1.51$

bungkus makan. Padahal restoran cepat saji tidak mengenakan biaya servis pada tagihannya, berbeda dengan restoran fine dining yang memang mengenakan biaya servis dan menggunakan alat makan berbahan keramik atau bahan berat lainnya. Merapikan bungkus makanan dan membuangnya ke tempat sampah merupakan kegiatan yang sama dengan membuang sampah ke tempatnya. Setelah kita terbiasa dengan kebiasaan tersebut, kita akan menjadi lebih peka terhadap kebersihan lingkungan, sehingga tidak hanya saat di restoran melainkan di manapun kita berada kita akan memiliki kesadaran untuk perilaku kebersihan dan menjaga lingkungan.

Dapat disimpulkan bahwa kesadaran dan kepedulian lingkungan memiliki pengaruh pada minat pelanggan dalam melakukan program tersebut dilihat dari komentar pelanggan yang setuju mengatakan bahwa mereka melakukan program tersebut secara sukarela karena telah terbiasa melakukannya saat pergi ke restoran cepat saji yang berada di luar negeri, banyak juga yang mengatakan bahwa beberes sisa bungkus makan sendiri adalah perilaku dasar dari kebersihan dan bermanfaat untuk meningkatkan kebiasaan baik pada masyarakat. Sedangkan masyarakat yang tidak setuju karena berfikir bahwa kita tidak perlu melakukan beberes sendiri karena sudah ada petugas kebersihan dan sudah membayar biaya pajak dan servis. Kemudian bagaimana aktivitas kampanye program juga mempengaruhi minat masyarakat dan meningkatkan kesadaran masyarakat akan manfaat baik dari program beberes sendiri di restoran cepat saji KFC, hal itu terlihat dari wawancara yang peneliti lakukan kepada salah satu dari karyawan KFC di Jakarta Timur yang mengatakan bahwa peningkatan sosialisasi dari pihak restoran seperti memasang poster atau stiker dan memberi merchandise membuat lebih banyak masyarakat mengenali program tersebut dan berinisiatif untuk melakukan beberes sendiri di restoran KFC Indonesia. Selain itu sarana penunjang program juga berperan penting pada berhasilnya program tersebut diterapkan dilihat dari komentar masyarakat di media sosial restoran KFC yang mengatakan bahwa waste container atau tempat sampah seharusnya diletakkan ditempat yang mudah terlihat dan diberikan sign ke arah tempat sampah agar memudahkan pelanggan untuk menemukan tempat sampah.

Sehingga penelitian ini bertujuan untuk mengetahui pengaruh kesadaran lingkungan terhadap tingkat penerimaan program beberes sendiri, mengetahui pengaruh ketersediaan sarana terhadap tingkat penerimaan program beberes sendiri, dan mengetahui pengaruh program kampanye terhadap tingkat penerimaan program beberes sendiri.

Setiap program kebersihan tentu memiliki pro dan kontra, peneliti melakukan wawancara terhadap beberapa karyawan restoran KFC yang mengatakan bahwa tidak semua pelanggan bersedia melakukan program beberes sendiri, kemudian dalam unggahan dari media sosial 
Jurnal Lebesgue : Jurnal Ilmiah Pendidikan Matematika, Matematika dan Statistika

Anisa Muthia, Tabah Heri Setiawan, Gerry Sastro

Volume 2, No. 1, April 2021 hal.22-33

DOI Artikel : 10.46306/lb.v2i1.51

restoran KFC Indonesia ditemukan kontroversi yaitu komentar masyarakat yang setuju dan tidak setuju dengan adanya program tersebut. Dari sinilah penulis melakukan penelitian tentang analisis tingkat penerimaan program beberes sendiri di restoran cepat saji KFC di Kab. Tangerang.

\section{METODE PENELITIAN}

Populasi pada penelitian ini adalah pelanggan restoran KFC Indonesia yang berada di Kabupaten Tangerang. Dalam tahap menentukan ukuran sampel, dikarenakan adanya keterbatasan peneliti menggunakan salah satu dari 10 times rule oleh Hair et al (2013) dalam Solihin dan Ratmono (2013:12) yang pada penelitian ini menghasilkan sampel minimum sebanyak 120 sampel. Kemudian dalam penyebaran dan pengumpulan kuesioner kepada responden secara offline di Restoran KFC Paramount Serpong dan secara online dengan media google form melalui media sosial didapatkan total 168 kuesioner.

Penelitian ini menggunakan metode analisis data Structural Equation Modelling - Partial Least Square (SEM-PLS) dengan menggunakan perangkat lunak SmartPLS Versi 3.3.2, dengan tahapan-tahapan penelitian sebagai berikut:

\section{HASIL DAN PEMBAHASAN}

\section{Hasil Data Penelitian}

\section{Hasil Evaluasi Pengukuran Model}

\section{Individual Item Reliability (Loading Factor)}

Uji loading factor memiliki batas maksimal diatas 0,5 , jika terdapat nilai indikator $<0.5$ maka harus dikeluarkan dan dilakukan penghitungan kembali. Terdapat 21 indikator diatas 0.5 dan dapat dikatakan valid.

\section{Internal Consistency Reliability (composite reliability)}

Uji reliabilitas dapat dilihat dari nilai composite reliability dengan nilai batas $>0.7$, dapat dilihat bahwa seluruh variabel memiliki nilai CR $>0.7$ sehingga sudah dapat dikatakan variabel.

Tabel 1. Nilai Composite Reliability

\begin{tabular}{ll}
\hline Pengukuran & Nilai \\
\hline KL (X1) & 0.787 \\
\hline SR (X2) & 0.818 \\
\hline KP (X3) & 0.833 \\
\hline TP (Y) & 0.923 \\
\hline
\end{tabular}


Jurnal Lebesgue : Jurnal Ilmiah Pendidikan Matematika, Matematika dan Statistika

Anisa Muthia, Tabah Heri Setiawan, Gerry Sastro

Volume 2, No. 1, April 2021 hal.22-33

DOI Artikel : 10.46306/lb.v2i1.51

\section{Average Variance Extracted (AVE)}

Uji AVE memiliki nilai batas 0.5, dapat dilihat bahwa seluruh variabel laten memiliki nilai AVE diatas 0.5 sehingga telah valid.

Tabel 2. Nilai Average Varianve Extract (AVE)

\begin{tabular}{ll}
\hline Pengukuran & Nilai \\
\hline KL $(X 1)$ & 0.552 \\
\hline SR (X2) & 0.602 \\
\hline KP (X3) & 0.625 \\
\hline TP (Y) & 0.502 \\
\hline
\end{tabular}

\section{Cross Loading}

Nilai cross loading antar indikator dan variabelnya harus menunjukkan nilai yang lebih tinggi dibandingkan dengan variabel lain.

Tabel 3. Nilai Cross Loading

\begin{tabular}{lcccc}
\hline & $\begin{array}{c}\text { KL } \\
(\mathrm{X} 1)\end{array}$ & $\mathrm{KP}(\mathrm{X} 3)$ & $\mathrm{SR}(\mathrm{X} 2)$ & $\mathrm{TP}(\mathrm{Y})$ \\
\hline KL.1 & 0.740 & 0.156 & 0.193 & 0.407 \\
\hline KL.3 & 0.706 & 0.154 & 0.077 & 0.389 \\
\hline KL.7 & 0.782 & 0.282 & 0.394 & 0.506 \\
\hline AKP.3 & 0.240 & 0.820 & 0.305 & 0.478 \\
\hline AKP.4 & 0.054 & 0.652 & 0.421 & 0.227 \\
\hline AKP.5 & 0.274 & 0.842 & 0.314 & 0.488 \\
\hline SR.1 & 0.319 & 0.366 & 0.835 & 0.325 \\
\hline SR.2 & 0.094 & 0.309 & 0.714 & 0.149 \\
\hline SR.3 & 0.266 & 0.309 & 0.817 & 0.282 \\
\hline TP.1 & 0.515 & 0.337 & 0.332 & 0.738 \\
\hline TP.2 & 0.415 & & & \\
\hline
\end{tabular}




\begin{tabular}{lcccc}
\hline & & 0.448 & 0.298 & 0.775 \\
\hline TP.3 & 0.453 & 0.499 & 0.269 & 0.789 \\
\hline TP.4 & 0.265 & 0.369 & 0.260 & 0.634 \\
\hline TP.6 & 0.445 & 0.290 & 0.316 & 0.712 \\
\hline TP.8 & 0.394 & 0.354 & 0.254 & 0.724 \\
\hline TP.9 & 0.581 & 0.351 & 0.217 & 0.763 \\
\hline TP.10 & 0.427 & 0.472 & 0.258 & 0.732 \\
\hline TP.11 & 0.484 & 0.273 & 0.154 & 0.633 \\
\hline TP.13 & 0.465 & 0.405 & 0.214 & 0.739 \\
\hline TP.14 & 0.298 & 0.272 & 0.128 & 0.604 \\
\hline TP.15 & 0.158 & 0.545 & 0.168 & 0.625 \\
\hline
\end{tabular}

5. Cross Loading Fornell-Lacker's

Pada nilai cross loading Fornell-Lacker's, nilai akar AVE antar konstruk harus lebih besar jika dibandingkan dengan nilai konstruk lainnya.

Tabel 4. Nilai Cross Loading Fornell-Lacker's

\begin{tabular}{ccccc}
\hline & \multicolumn{1}{c}{ KL } & KP (X3) & SR (X2) & TP (Y) \\
\hline KL (X1) & 0.743 & & & \\
\hline KP (X3) & 0.274 & 0.776 & & \\
\hline SR (X2) & 0.317 & 0.415 & 0.790 & \\
\hline TP (Y) & 0.590 & 0.545 & 0.341 & 0.708 \\
\hline
\end{tabular}

\section{Hasil Evaluasi Struktural Model}

\section{Path Coefficient}

Pengujian ini dilakukan untuk melihat hubungan antar variabel (konstruk) dan apakah hipotesa yang ada mempunyai arah positif atau negatif.

"Path coefficients memiliki nilai standar (standardized values) antara -1 sampai +1 . Nilai path coefficients yang mendekati +1 merepresentasikan hubungan hipotesa yang positif (dan 
Jurnal Lebesgue : Jurnal Ilmiah Pendidikan Matematika, Matematika dan Statistika

Anisa Muthia, Tabah Heri Setiawan, Gerry Sastro

Volume 2, No. 1, April 2021 hal.22-33

DOI Artikel : 10.46306/lb.v2i1.51

begitupun sebaliknya untuk nilai yang negatif) dan hampir selalu signifikan secara statistik" (hair et al., 2014).

Tabel 5. Nilai Uji Path Coefficient

\begin{tabular}{lll}
\hline Pengukuran & Path Coefficient & Hubungan \\
\hline $\begin{array}{l}\text { KL }(\mathrm{X} 1) \rightarrow \mathrm{TP} \\
(\mathrm{Y})\end{array}$ & 0.471 & Positif \\
\hline $\begin{array}{l}\mathrm{SR}(\mathrm{X} 2) \rightarrow \mathrm{TP} \\
(\mathrm{Y})\end{array}$ & 0.023 & Positif \\
\hline $\begin{array}{l}\mathrm{KP}(\mathrm{X} 3) \rightarrow \mathrm{TP} \\
(\mathrm{Y})\end{array}$ & 0.406 & Positif \\
\hline
\end{tabular}

2. Coefficient of Determination $\left(R^{2}\right)$

Pengujian ini dilakukan untuk mengukur seberapa besar variabel laten dependen dijelaskan dan dipengaruhi oleh variabel laten independen.

"Pada penelitian ilmiah, $\mathrm{R}^{2}$ dengan nilai $0,75,0,5$ atau 0,2 untuk variabel laten endogen dapat dijadikan sebagai Rule of Thumb. Dengan standar 0,75 dinilai kuat, kisaran 0,50 dikatakan moderat dan dibawah 0,25 dikatakan lemah" (hair et al., 2014).

Tabel 6. Nilai Uji Coefficient of Determination $\left(R^{2}\right)$

\begin{tabular}{lll}
\hline & $\mathrm{R}^{2}$ & Keterangan \\
\hline Tingkat Penerimaan $(\mathrm{Y})$ & 0.507 & Moderat
\end{tabular}

\section{T-Statistic (Signifikansi)}

Pengujian ini dilakukan dengan menggunakan metode boostraping dengan uji two-tailed dengan tingkat signifikansi sebesar 5\% untuk menguji pengukuran penelitian. Pengukuran dinyatakan signifikan jika nilai $t$-statistic lebih besar dari 1,96 .

Tabel 7. Nilai Uji T-Statistic

\begin{tabular}{lcl}
\hline \multicolumn{1}{c}{ Hipotesis } & T-Statistic & Keterangan \\
\hline $\mathrm{KL}(\mathrm{X} 1) \rightarrow \mathrm{TP}$ & 6.324 & \\
$(\mathrm{Y})$ & & Signifikan \\
\hline $\mathrm{SR}(\mathrm{X} 2) \rightarrow \mathrm{TP}$ & 0.332 & \\
$(\mathrm{Y})$ & & Tidak Signifikan \\
\hline
\end{tabular}




$$
\mathrm{KP}(\mathrm{X} 3) \rightarrow \mathrm{TP}
$$

\subsection{3}

Signifikan

\section{4. $\quad$ Effect Size $\left(f^{2}\right)$}

Pengujian ini dilakukan untuk memprediksi pengaruh variabel tertentu terhadap variabel lainnya dalam struktur model penelitian. "Pengaruh tersebut diklasifikasikan menjadi tiga bagian yaitu nilai $\mathrm{f}^{2}$ memiliki batasan dibawah 0,02 untuk pengaruh kecil, diatas 0,15 untuk pengaruh menengah dan diatas 0,35 untuk pengaruh besar" (Hair et al., 2017).

Tabel 8. Nilai Uji Effect Size $\left(f^{2}\right)$

\begin{tabular}{lll}
\hline \multicolumn{1}{c}{ Hipotesis } & $f^{2}$ & Keterangan \\
\hline KL $(\mathrm{X} 1) \rightarrow \mathrm{TP}$ & & Besar \\
$(\mathrm{Y})$ & 0.395 & \\
\hline $\mathrm{SR}(\mathrm{X} 2) \rightarrow \mathrm{TP}$ & & Kecil \\
$(\mathrm{Y})$ & 0.001 & \\
\hline $\mathrm{KP}(\mathrm{X} 3) \rightarrow \mathrm{TP}$ & & Menengah \\
$(\mathrm{Y})$ & 0.269 & \\
\hline
\end{tabular}

\section{Predictive Relevance $\left(Q^{2}\right)$}

Pengujian ini dilakukan dengan menggunakan metode blindfolding untuk dapat mengetahui apakah variabel tertentu yang digunakan dalam model penelitian mempunyai keterkaitan secara prediktif (predictive relevance) dengan ambang batas pengukuran di atas nol (Hair et al., 2017).

Tabel 9. Nilai Uji Predictive Relevance $\left(Q^{2}\right)$

\begin{tabular}{lll}
\hline & $\mathrm{Q}^{2}(=1-\mathrm{SSE} / \mathrm{SSO})$ & Keterangan \\
\hline $\mathrm{TP}(\mathrm{Y})$ & 0.243 & Predictive \\
\hline
\end{tabular}

\section{Fit Model}

Pengujian fit model dilakukan untuk menunjukkan seberapa baik model yang dimiliki suatu penelitian. "Nilai fit model dapat dilihat pada PLS Algorithm pada nilai NFI. NFI menghasilkan nilai antara 0 sampai 1 . Semakin mendekati 1 maka semakin baik model yang digunakan dalam penelitian" (Hair et al., 2017). 
Tabel 10. Nilai Uji Fit Model

\begin{tabular}{lll}
\hline Pengukuran & NFI & Presentase \\
\hline Model Estimasi & 0.658 & $65,8 \%$ \\
\hline
\end{tabular}

\section{Pembahasan}

\section{Pembahasan Evaluasi Pengukuran Model}

Measurement model atau Outer Model digunakan untuk merepresentasikan hubungan antara konstruk variabel laten dengan pengukurnya (indikator). Evaluasi pengukuran model adalah syarat yang diperlukan sebelum perhitungan selanjutnya yaitu evaluasi struktural model, uji hipotesis yang melibatkan struktural diantara konstruk hanya akan reliabel dan valid jika pengukuran pada meassurement model sudah sesuai dengan standar nilai yang telah ditentukan (Hair et al., 2014).

Berdasarkan hasil analisis outer model yang telah dijabarkan sebelumnya, model yang diajukan peneliti telah memiliki tingkat reliabilitas dan validitas yang baik. Hal ini ditunjukkan dengan seluruh indikator yang memiliki outer loading diatas 0,6 serta composite reliability diatas 0,7. Selain itu juga seluruh indikator memiliki nilai AVE diatas 0,5 serta cross loading dan Fornel-Lacker's yang memiliki kriteria sesuai syarat yang ada.

\section{Pembahasan Evaluasi Struktural Model}

\section{Path Coefficient}

a. $\mathrm{KL}(\mathrm{X} 1) \rightarrow \mathrm{TP}(\mathrm{Y})$ memiliki nilai path coefficient 0,471 , sehingga dapat dikatakan kesadaran lingkungan dengan tingkat penerimaan pada program beberes sendiri memiliki hubungan yang positif.

b. SR (X2) $\rightarrow$ TP (Y) memiliki nilai path coefficient 0,023 , sehingga dapat dikatakan sarana dengan tingkat penerimaan program beberes sendiri memiliki hubungan yang positif.

c. $\mathrm{KP}(\mathrm{X} 3) \rightarrow \mathrm{TP}(\mathrm{Y})$ memiliki nilai path coefficient 0.406 , sehingga dapat dikatakan kampanye program dengan tingkat penerimaan program beberes sendiri memiliki hubungan yang positif.

\section{Coefficient of Determination $\left(R^{2}\right)$}

Pada penelitian ini terdapat satu variabel laten dependen yaitu Tingkat Penerimaan. Dapat dilihat pada tabel 4.15 bahwa nilai $\mathrm{R}^{2}$ adalah 0,507 (50,7\%). Dengan demikian dapat dijelaskan bahwa kemampuan variabel independen (KL, SR dan KP) menjelaskan variabel dependen (TP) secara moderat. 
Jurnal Lebesgue : Jurnal Ilmiah Pendidikan Matematika, Matematika dan Statistika

Anisa Muthia, Tabah Heri Setiawan, Gerry Sastro

Volume 2, No. 1, April 2021 hal.22-33

DOI Artikel : $10.46306 / 1 b . v 2 \mathrm{i} 1.51$

\section{T-Statistic (Signifikansi)}

a. $\mathrm{KL}(\mathrm{X} 1) \rightarrow \mathrm{TP}(\mathrm{Y})$ memiliki nilai t-statistic 6,324, sehingga dapat dikatakan bahwa kesadaran lingkungan seseorang memiliki pengaruh yang signifikan terhadap tingkat penerimaan program beberes sendiri.

b. SR (X2) $\rightarrow$ TP (Y) memiliki nilai t-statistic 0,332, sehingga dapat dikatakan bahwa ketersediaan sarana memiliki pengaruh yang tidak signifikan terhadap tingkat penerimaan program beberes sendiri.

c. $\mathrm{KP}(\mathrm{X} 3) \rightarrow \mathrm{TP}(\mathrm{Y})$ memiliki nilai $t$-statistic 4,353, sehingga dapat dikatakan bahwa aktivitas kampanye program yang dilakukan oleh restoran KFC memiliki pengaruh yang signifikan terhadap tingkat penerimaan program beberes sendiri.

\section{Effect Size $\left(f^{2}\right)$}

a. Pengukuran pertama KL $(\mathrm{X} 1) \rightarrow \mathrm{TP}(\mathrm{Y})$ memiliki nilai $\mathrm{f}^{2}$ diatas 0,35 yaitu 0,395 . Hal ini menunjukkan bahwa kesadaran lingkungan seseorang memiliki pengaruh yang besar terhadap tingkat penerimaan program beberes sendiri.

b. Pengukuran kedua SR $(\mathrm{X} 2) \rightarrow \mathrm{TP}(\mathrm{Y})$ memiliki nilai $\mathrm{f}^{2}$ dibawah 0,02 yaitu 0,001 . Hal ini menunjukkan bahwa ketersediaan sarana di restoran memiliki pengaruh kecil terhadap tingkat penerimaan program beberes sendiri.

c. pengukuran ketiga $\mathrm{KP}(\mathrm{X} 3) \rightarrow \mathrm{TP}(\mathrm{Y})$ nilai $\mathrm{f}^{2}$ diatas 0,15 yaitu 0,269 . Hal ini menunjukkan bahwa aktivitas kampanye program oleh restoran KFC memiliki pengaruh yang menengah terhadap tingkat penerimaan program beberes sendiri.

\section{Predictive Relevance $\left(Q^{2}\right)$}

Nilai tersebut untuk mengetahui apakah variabel tertentu yang digunakan dalam model penelitian mempunyai keterkaitan secara prediktif. Dapat diketahui bahwa pengukuran variabel laten dependen yaitu tingkat penerimaan memiliki nilai predictive relevance lebih dari 0 yaitu 0,243 maka seluruh jalur yang ada dalam penelitian ini memiliki keterkaitan prediktif dengan variabel lainnya serta menunjukkan nilai observasi yang baik.

\section{Fit Model}

Nilai tersebut digunakan untuk menunjukkan seberapa baik model yang dimiliki suatu penelitian. menghasilkan nilai antara 0 sampai 1 . Semakin mendekati 1 maka semakin baik model yang digunakan dalam penelitian. Didapatkan perhitungan fit model dengan nilai adalah 0, $658(65,8 \%)$. Dengan demikian dapat diketahui bahwa model dalam penelitian ini sudah cukup baik. 
Jurnal Lebesgue : Jurnal Ilmiah Pendidikan Matematika, Matematika dan Statistika

Anisa Muthia, Tabah Heri Setiawan, Gerry Sastro

Volume 2, No. 1, April 2021 hal.22-33

DOI Artikel : 10.46306/lb.v2i1.51

\section{KESIMPULAN}

Kesadaran lingkungan memiliki pengaruh positif, kuat dan signifikan terhadap tingkat penerimaan program beberes sendiri di restoran cepat saji KFC di Kabupaten Tangerang. Ketersediaan sarana memiliki pengaruh positif yang lemah serta tidak signifikan terhadap program beberes sendiri di restoran cepat saji KFC di Kabupaten Tangerang. Kampanye program memiliki pengaruh positif menengah serta signifikan terhadap tingkat penerimaan program beberes sendiri di restoran cepat saji KFC di Kabupaten Tangerang. Kesadaran lingkungan, faktor ketersediaan sarana dan faktor aktivitas kampanye program memiliki pengaruh signifikan terhadap tingkat penerimaan program beberes sendiri di restoran cepat saji KFC di Kabupaten Tangerang dengan dipengaruhi sebesar 50,7\%. Sedangkan 49,3\% nya dapat dipengaruhi oleh faktor-faktor lain yang tidak digunakan dalam penelitian ini. Ketiga faktor tersebut dapat memprediksikan tingkat penerimaan dengan baik dan memiliki kecocokan model sebesar $65,8 \%$.

\section{DAFTAR PUSTAKA}

Fikri, A. J., Aini, S., Sukandar, R. S., Safiyanah, I., \& Listiasari, D. (2021). OPTIMALISASI KEUNTUNGAN PRODUKSI MAKANAN MENGGUNAKAN PEMROGRAMAN LINIER MELALUI METODE SIMPLEKS. Jurnal Bayesian: Jurnal Ilmiah Statistika dan Ekonometrika, 1(1), 1-16.

Hair, J. F., Hult, G. T., Ringle, C. M., \& Sarstedt, M. 2014. A Primer on Partial Least Squares Structural Equation Modeling (PLS-SEM). Amerika: SAGE Publications.

Kotler, P. (2010). Marketing 3.0. Jakarta: Erlangga.

Purwandari, D. (2020). PEMODELAN REGRESI LATEN PADA EFEK PLASEBO MEMAKAI METODE MAXIMUM LIKELIHOOD. Jurnal Lebesgue: Jurnal Ilmiah Pendidikan Matematika, Matematika dan Statistika, 1(3), 193-198.

Primastika, W. 2019. Dukungan \& Gerutuan KFC: Makan Sendiri, Beres-Beres pun Sendiri. Diambil kembali dari Tirto.id: https://tirto.id/dukungan-gerutuan-ke-kfc-makan-sendiriberes-beres-pun-sendiri-deM5, diakses 5 Agustus 2020.

Rahayu, P. I., \& Sihombing, P. R. (2021). PENGELOMPOKAN PROVINSI DI INDONESIA BERDASARKAN FASILITAS KESEHATAN MENGGUNAKAN METODE TWO STEP CLUSTER. Jurnal Bayesian: Jurnal Ilmiah Statistika dan Ekonometrika, 1(1), 77-83.

Sanchez, M. J., \& Lafuente, R. 2010. Defining and Measuring Environmental Consciousness. Revista Internacional de Sociologia (RIS) Journal. Vol. 68, No. 3, hlm 731-755.

Solihin, M., \& Ratmono, D. 2013. Analisis SEMPLS dengan WarpPLS 3.0 Untuk Hubungan Nonlinier Dalam Penelitian Sosial dan Bisnis. Yogyakarta: Penerbit Andi.

Sudibyo, N. A., Iswardani, A., Septyanto, A. W., \& Wicaksono, T. G. (2020). Prediksi Inflasi Di Indonesia Menggunakan Metode Moving Average, Single Exponential Smoothing Dan Double Exponential Smoothing. Jurnal Lebesgue: Jurnal Ilmiah Pendidikan Matematika, Matematika dan Statistika, 1(2), 123-129.

Supriyanti, A. (2020). PREDIKSI JUMLAH CALON PESERTA DIDIK BARU MENGGUNAKAN METODE DOUBLE EXPONENTIAL SMOOTHING DARI BROWN:(Study Kasus: SD Islam Al-Musyarrofah Jakarta). Jurnal Lebesgue: Jurnal Ilmiah Pendidikan Matematika, Matematika Dan Statistika, 1(1), 56-62. 
Volume 2, No. 1, April 2021 hal.22-33

DOI Artikel : 10.46306/lb.v2i1.51

Ulfa, G. S. 2017. Efektivitas Instagram "EARTH HOUR BOGOR" Sebagai Media Kampanye Lingkungan. Unpublished Thesis. Bogor: Insitut Pertanian Bogor.

Wikipedia. 2020. Kebersihan. Diambil kembali dari Wikipedia Indonesia: https://id.wikipedia.org/wiki/Kebersihan, diakses 5 Agustus 2020. 